\title{
PRINCÍPIOS FUNDAMENTAIS E MODELOS DE TRANSFERÊNCIA DE ENERGIA INTER E INTRAMOLECULAR
}

\author{
Ernesto R. Souza e Fernando A. Sigoli* \\ Instituto de Química, Universidade Estadual de Campinas, CP 6154, 13083-970 Campinas - SP, Brasil
}

Recebido em 1/11/11; aceito em 17/4/12; publicado na web em 10/8/12

\begin{abstract}
FUNDAMENTAL PRINCIPIA AND MODELS OF INTER AND INTRAMOLECULAR ENERGY TRANSFER. This work outlines the historic development of the concept and main theories of energy transfer, as well as the principal experiments carried out to confirm or refute the proposed theories. Energy transfer in coordination compounds is also discussed with a focus on rare earth systems.
\end{abstract}

Keywords: energy transfer; Förster mechanism; Dexter mechanism.

\section{INTRODUÇÃO}

O termo transferência de energia é usado para descrever a transferência de excitação eletrônica de uma espécie química (átomo, molécula, íon, radical) para outra, igual ou diferente, ou entre grupos de uma mesma molécula. ${ }^{1}$ Este fenômeno comumente constitui uma parte de processos mais complexos, tais como fluorescência ${ }^{2,3}$ etc. Assim, a compreensão do modo como se dá a transferência de energia e quais são as variáveis que a descrevem em cada circunstância é importante para a elucidação de fenômenos que abrangem desde os vários tipos de luminescência até fotossíntese.

Na literatura são apresentadas muitas aplicações, em áreas muito diversas, das teorias já desenvolvidas e consolidadas sobre transferência de energia. A teoria de Förster tem extensas aplicações médicas, biológicas e bioquímicas ${ }^{4}$ e, também, é utilizada para a detecção e caracterização da separação de fases em bicamadas lipídicas, ${ }^{5}$ bem como para a detecção de heterogeneidade e outras características. Outra área de aplicação da teoria de Förster se encontra na utilização de quantum dots semicondutores como sondas de processos biológi$\cos .^{6} \mathrm{O}$ modelo de Dexter se aplica especialmente a sistemas onde a distância de transferência é muito curta e onde há sobreposição orbital entre as espécies envolvidas apresentando, assim, conjugação. ${ }^{7} \mathrm{Um}$ exemplo recente é o apresentado por Mao e Wang, ${ }^{8}$ que confirmaram o mecanismo de transferência de energia para um fósforo à base de aluminato de lantânio codopado com manganês(II) e európio(III).

Em se tratando de transferência de energia intramolecular, ou seja, entre espécies de uma mesma molécula, complexos metálicos são especialmente estudados por sua grande variedade. Entre eles, os complexos contendo íons terras raras (TR(III)) têm sua luminescência explicada pela transferência de energia oriunda do ligante, fenômeno que é conhecido como efeito antena, que promove uma intensificação da intensidade luminescente do íon metálico central graças à eficiente absorção de energia por parte do ligante. O processo através do qual a energia parte do ligante até alcançar o nível emissor do íon TR(III) de diferentes complexos pode ser explicado por basicamente três mecanismos, onde a diferença entre eles é a eficiência de fenômenos como conversão interna, transferência de energia ligante-íon TR(III) e retrotransferência íon TR(III)-ligante.

*e-mail: fsigoli@iqm.unicamp.br

\section{BREVE HISTÓRICO DO ESTUDO SOBRE TRANSFERÊNCIA DE ENERGIA}

Na década de 1920, Perrin desenvolveu um modelo de transferência de energia baseado na ressonância entre os dipolos elétricos do doador e do receptor, ${ }^{9}$ mas algumas atribuições que fez em seu trabalho como, por exemplo, a de que moléculas idênticas apresentam exatamente a mesma frequência de oscilação, o levaram a calcular um raio para transferência de energia exageradamente grande, da ordem de centenas e, às vezes, de milhares de Ångströms. Posteriormente, utilizando-se da física quântica e da teoria de perturbação, Förster ${ }^{10}$ adaptou o modelo de Perrin e recalculou a distância para a transferência de energia para um valor muito próximo do verificado experimentalmente por outros pesquisadores. ${ }^{11}$ Como o modelo de Förster descreve apenas processos governados por interações de dipolo-dipolo, Dexter estendeu este modelo para os casos onde a transferência de energia por ressonância de dipolos é proibida ou apresenta eficiência muito baixa. ${ }^{12}$ Desta forma, o modelo de Dexter é aplicado para sistemas multipolares, como dipolo-quadrupolo e quadrupolo-quadrupolo, que apresentam uma dependência em relação à distância entre doador e receptor de até quatro ordens de grandeza maior do que a observada em sistemas onde o mecanismo de Förster é dominante.

A simplicidade do modelo de Perrin o torna muitas vezes o mais indicado para fins didáticos. Simplicidade, no entanto, que não significa pobreza ou simploriedade, tanto assim que seus princípios o tornam aplicável para o desenvolvimento de programas computacionais para visualização de mecanismos de luminescência. ${ }^{13}$

Estes modelos vêm sendo estudados especialmente em sistemas em matéria condensada, onde o modelo de Förster tem uma especial utilidade em sistemas biológicos, podendo-se observar, por exemplo, a interação em função do tempo entre dois grupos cromóforos em uma mesma proteína. ${ }^{4}$ Já o modelo de Dexter é verificado comumente em sistemas sólidos, ${ }^{14}$ onde mecanismos de interação dipolo-dipolo podem ser proibidos por simetria local e onde as distâncias doador-receptor são menores.

\section{FUNDAMENTOS}

Tratando-se da transferência de energia intermolecular, há fundamentalmente dois processos, denominados radiativo e não radiativo. O processo radiativo consiste em duas etapas consecutivas: a emissão de radiação por parte do doador e a posterior absorção desta radiação por parte do receptor, como se segue: 


$$
\begin{aligned}
& D^{*} \rightarrow D+h v \\
& R+h v \rightarrow R^{*}
\end{aligned}
$$

onde D é a espécie doadora e R é a espécie receptora (Figura 1). A eficiência deste processo é governada principalmente pela sobreposição entre o espectro de emissão do doador e o espectro de absorção do receptor. Ou seja, fatores extrínsecos como a viscosidade da solução não interferem no processo. Na verdade, este processo consiste em duas absorções seguidas de emissões, onde a diferença de energia entre elas é o comprimento da onda da radiação absorvida pelo doador e pelo receptor. Se o receptor tem baixa absortividade na região da radiação incidente, então o doador funciona como um conversor de radiação, emitindo-a não direcionalmente.

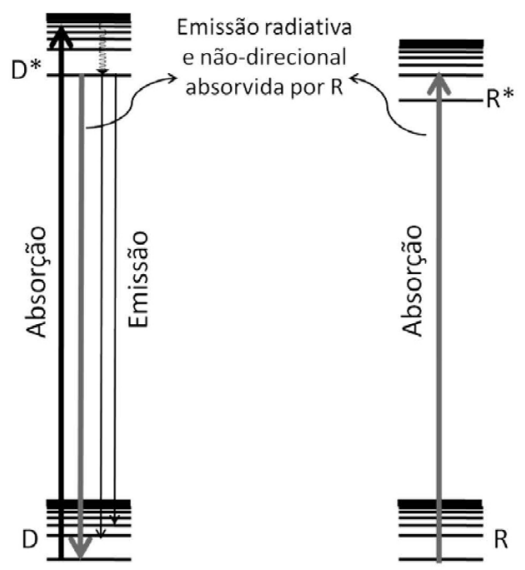

Figura 1. Esquema ilustrando o processo de transferência de energia radiativo de energia, onde o doador excitado $(D *)$ emite radiativamente a energia, que excita o receptor $(A)$

A transferência de energia não radiativa consiste em uma só etapa envolvendo simultaneamente o decaimento do doador e a excitação do receptor:

$$
D^{*}+R \rightarrow D+R^{*}
$$

Assim, devido à interação entre as duas espécies, a presença do receptor influencia tanto no rendimento da emissão do doador quanto no tempo de decaimento de ambos. A energia transferida pelo doador não é mais não direcional, como no caso da emissão radiativa, mas se dá pela interação entre doador e receptor, por isso este processo é direcional (Figura 2).

As relações entre os tempos de vida dos processos envolvidos entre a excitação do doador e o retorno do receptor ao estado fundamental são de grande importância para determinar a probabilidade de transferência de energia em um dado sistema. ${ }^{15}$ Por exemplo, se um doador apresenta baixo tempo de vida de fluorescência e uma baixa taxa de transferência singleto excitado-tripleto então é mais provável que este doador apresente fluorescência ao invés de fosforescência ou de transferência de energia para um receptor. ${ }^{16}$

O primeiro tratamento teórico, baseado na física clássica, para transferência de energia entre moléculas em solução foi desenvolvido por Perrin, que conjecturou que a energia é transferida de uma molécula para outra através da interação entre os dipolos de oscilação das moléculas envolvidas, e estimou que a transferência de energia poderia ocorrer a distâncias de até $\lambda / 2 \pi$, onde $\lambda$ é o comprimento de onda do campo elétrico oscilante. ${ }^{9}$ Além disso, assumiu que duas moléculas idênticas apresentam exatamente a mesma frequência fundamental de oscilação, ou seja, dois osciladores em ressonância, e que a energia é transferida de modo similar a dois pêndulos

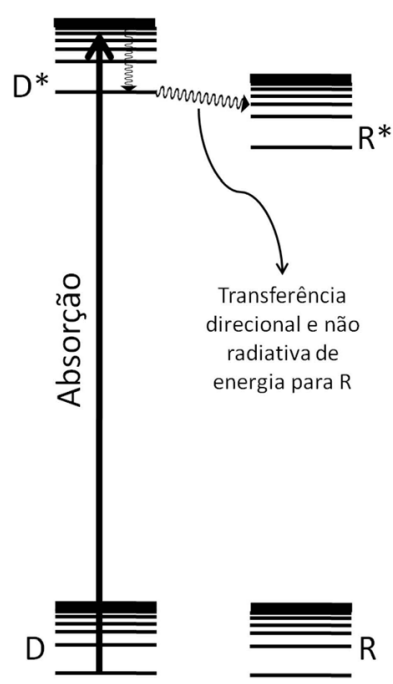

Figura 2. Esquema ilustrando o processo de transferência de energia não radiativo, onde o doador excitado $\left(D^{*}\right)$ transfere energia diretamente para o receptor $(A)$

mecanicamente acoplados. Tais considerações levaram à previsão acerca das distâncias de transferência na ordem de várias centenas de Ångströms, pois concebeu os espectros de emissão do doador e de absorção do receptor como espectros de linhas, e não considerou seu alargamento natural, também causado pela interação com o solvente. ${ }^{17}$

Anos depois, T. Förster desenvolveu seu modelo tratando a transferência de energia segundo a mecânica quântica, incluindo um potencial perturbacional no cálculo do hamiltoniano do sistema doador-receptor. Expandindo a teoria de Perrin, Förster mostrou que a distância na qual ocorre a transferência de energia é mensurável e procurou utilizar grandezas espectroscópicas e físicas que tornassem possível o cálculo desta distância limite.

Apesar de haver estudos aprofundados sobre processos de transferência de energia em fase gasosa ${ }^{18}$ e transferência pelo processo radiativo, ${ }^{1}$ este trabalho aborda os fundamentos teóricos e aplicações práticas dos modelos propostos para transferência de energia pelo processo não radiativo em matéria condensada.

\section{TEORIA DE FÖRSTER}

O modelo de transferência de energia proposto por Förster consiste na transferência não radiativa da energia de um doador no estado excitado para um receptor, devido a interações de tipo dipolo-dipolo de longo alcance entre o doador e o receptor. ${ }^{10}$ Para que ocorra a transferência de energia é necessária uma condição ressonante entre as oscilações dos campos elétricos do estado excitado do doador e do estado fundamental do receptor, além da sobreposição entre a emissão do doador e a absorção do receptor e de uma orientação espacial entre os dipolos elétricos dos dois estados diretamente envolvidos.

A teoria de Förster baseia-se em grandezas experimentalmente acessíveis, como fluorescência, absorção e tempo de vida, e foi formulada para meios viscosos onde as translações moleculares são minimizadas. A taxa de transferência de energia $\left(K_{t}\right)$ do doador para o receptor é dada por

$$
K_{t}=\frac{1}{\tau_{D}}\left(\frac{R_{0}}{r}\right)^{6}
$$

onde $\tau_{D}$ é o tempo de decaimento do estado excitado do doador na ausência do receptor, $r$ a distância entre o doador e o receptor e $R_{0}$ o raio ou distância de Förster, definido como a distância entre o doador e o receptor na qual a eficiência da transferência é igual a 
$50 \%$. Quando a distância entre o doador e o receptor é igual ao raio de Förster $\left(R_{0}=r\right)$, então a taxa de transferência de energia é igual à taxa de decaimento do doador na ausência do receptor $\left(K_{t}=\tau_{D}^{-1}\right)$. Nota-se também na Equação 1, a forte dependência da taxa de transferência de energia em função da sexta potência da distância entre o doador e o receptor. Como a interação dipolo-dipolo é uma função da distância $r$ que varia com $r^{3}$, a probabilidade da transferência, ou seja, seu quadrado, varia com $r^{6}$. Portanto, pode-se escrever:

$$
K_{t}=\frac{Q_{D} K^{2}}{\tau_{D^{r}}}\left(\frac{9000 \ln 10}{128 \pi^{5} N n^{4}}\right)^{6} \int_{0}^{\infty} F_{D}(\lambda) \in_{R}(\lambda) \lambda^{4} d \lambda
$$

onde $Q_{D}$ é o rendimento quântico do doador na ausência do receptor, $N$ o número de Avogadro, $n$ o índice de refração do meio entre o doador e o receptor, $F_{D}(\lambda)$ a intensidade normalizada da fluorescência do doador no comprimento de onda $1, \in_{R}(\lambda)$ o coeficiente de extinção do receptor no comprimento de onda . A integral da Equação 2 é chamada integral de sobreposição ou $J(\lambda)$ e expressa o grau de sobreposição espectral entre a emissão do doador e a absorção do receptor (Figura 3). Como é adimensional, $\in_{R}(\lambda)$ é dado em $\mathrm{L} \mathrm{mol}^{-1}$ $\mathrm{cm}^{-1} \mathrm{e} \lambda^{4}$ pode ser dado em $\mathrm{cm}^{4}$, então $J(\lambda)$ é expresso em $\mathrm{L} \mathrm{mol}^{-1} \mathrm{~cm}^{3}$.

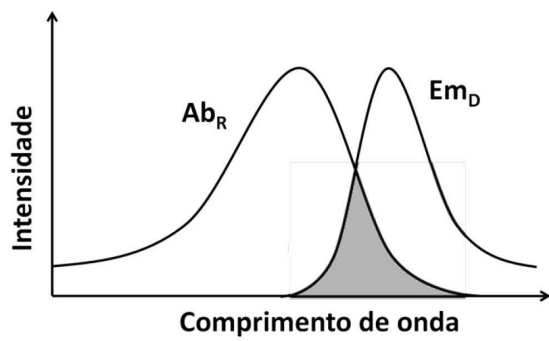

Figura 3. Integral de sobreposição corresponde à área simultaneamente sob os espectros normalizados de absorção do receptor $\left(A b_{R}\right)$ e de emissão do doador $\left(E_{D}\right)$

O termo $K^{2}$ é o fator que descreve a orientação dos dipolos do doador e do receptor no espaço, e é dado por

$$
K^{2}=\left(\cos \phi_{D R}-3 \cos \phi_{D} \cos \phi_{R}\right)^{2}
$$

onde $\cos \phi_{D R}$ é o ângulo entre os momentos de dipolo de transição do doador e do receptor, $\cos \phi_{D}$ o ângulo entre o momento de dipolo do doador e o vetor que o liga ao receptor e $\cos \phi_{R}$ o ângulo entre o momento de dipolo do receptor e o vetor que o liga ao doador (Figura 4), sendo que o momento de dipolo da molécula é maior no estado excitado do que no estado fundamental. ${ }^{19}$

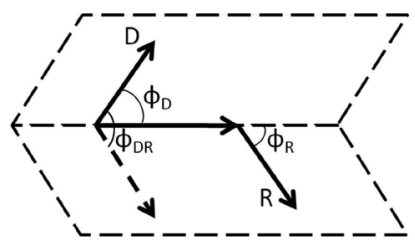

Figura 4. Dependência do fator de orientação em função das direções dos dipolos de transição do doador $(D)$ e do receptor $(R)$. Adaptada da ref. 17

O valor de $K^{2}$, em função da orientação relativa entre os dipolos do doador e do receptor, pode variar de 0 a 4; para dipolos de transição paralelos e colineares, $K^{2}=4$, e para dipolos paralelos, $K^{2}=1$. Se tanto o doador como o receptor rotacionam livremente em um tempo relativamente curto se comparado com o tempo de vida do estado excitado do doador, então assume-se que $K^{2}=2 / 3$. Como no cálculo do raio de Förster toma-se ${ }^{6} \sqrt{K^{2}}$, para a variação de $K^{2}$ no intervalo de 1 a 4 , o valor calculado de $K^{2}=2 / 3$ gera um erro de no máximo $35 \%$. Este valor assumido para $K^{2}$ é o valor para transferências de energia onde o doador e o receptor rotacionam randomicamente.

Como $K_{t}$ é dependente de $r$, a Equação 2 é escrita normalmente em função de $R_{0}$, como se segue que

$$
R_{0}{ }^{6}=\frac{9000(\ln 10) K^{2} Q_{D}}{128 \pi^{5} N n^{4}} \int_{0}^{\infty} F_{D}(\lambda) \in_{R}(\lambda) \lambda^{4} d \lambda,
$$

Esta expressão permite calcular o raio de Förster através de propriedades espectrais do doador e do receptor. A Equação 4 pode ser reescrita como

$$
R_{0}=978\left[K^{2} n^{-4} Q_{D} J(\lambda)\right]^{1 / 6},
$$

onde $R_{0}$ é expresso em $\AA$.

A Equação 2 assume que as moléculas (dipolos) são pontuais, o que não é uma limitação visto que normalmente $R_{0}$ é muito maior que as dimensões moleculares. Além disso, como o tempo de vida da transferência de energia é muito menor que o tempo das vibrações moleculares, assume-se que as moléculas permanecem estáticas durante o processo de transferência de energia. Outras aproximações a se destacar são: ignora-se a possibilidade de transferência de energia a partir de níveis vibracionais mais elevados do doador; o número de doadores excitados é muito menor que o número de doadores ou de receptores no estado fundamental; despreza-se a interação doador-doador e, ignora-se a possibilidade da presença do receptor influenciar no espectro de fluorescência do doador e da presença do doador influenciar no espectro de absorção do receptor. ${ }^{1}$

A eficiência da transferência de energia $(E)$ é a fração de fótons absorvidos pelo doador que são transferidos para o receptor, e é dada por

$$
E=\frac{K_{t}}{\tau_{D}^{-1}+K_{t}},
$$

Substituindo a Equação 1 na Equação 6, tem-se que

$$
R=\frac{R_{0}^{6}}{R_{0}^{6}+r^{6}}
$$

Quando $R_{0}$ é muito pequeno, isto é, de ordem molecular, acaba representando um limite muito pequeno para a transferência de energia no sistema em questão (Figura 5). Assim, nessas condições, outros termos que não o acoplamento entre dipolos podem ser mais relevantes e acabar por aumentar a distância de transferência; além disso, os valores de $R_{0}$ em soluções são maiores porque há a inclusão de um termo de difusão. ${ }^{1}$

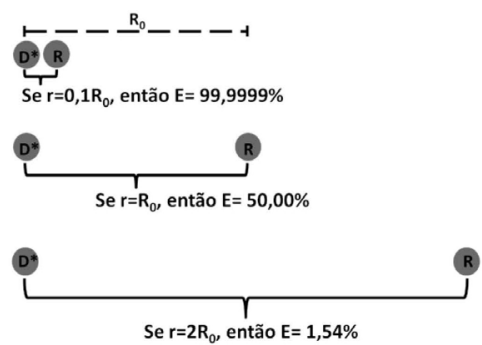

Figura 5. Ilustração sobre a eficiência da transferência de energia de Förster em função da distância doador-receptor

Stryer e Haugland ${ }^{11}$ conduziram um experimento muito interessante para verificar a proposta de Förster, que consistiu em manter 
o doador e o receptor separados por um oligômero de comprimento conhecido, variando-se o tamanho deste de 12 a $46 \AA$ A. A conclusão foi de que o sistema estudado apresentava uma excelente concordância com a dependência de $r^{6}$ por parte da eficiência, segundo descrito pela teoria de Förster.

Oliveira e coautore ${ }^{19}$ determinaram os raios críticos de transferência de energia para corantes em diferentes soluções alcoólicas. Utilizaram três diferentes medições experimentais - sobreposições espectrais, perfil de decaimento radiativo e intensidades relativas de emissão - e encontraram valores entre 40 e $90 \AA$ A, com uma boa correlação entre os valores de cada sistema.

Estudos em estado sólido permitem a avaliação da influência de variáveis físicas sobre a transferência de energia, tais como a pressão, sem modificar drasticamente outras variáveis como distâncias moleculares, como acontece no caso dos gases. Em 1972, Johnson e Offen ${ }^{20}$ estudaram o efeito da pressão sobre a transferência de energia do pireno para o perileno em matriz de polimetilmetacrilato e verificaram que há diminuição na eficiência da transferência de energia singleto do pireno para o singleto do perileno em função do aumento de pressão. Os fatores responsáveis por essa diminuição de eficiência, em ordem crescente de importância, são: a diminuição da sobreposição espectral entre a fluorescência do pireno e a absorção do perileno, o aumento do índice de refração do meio e a diminuição do tempo de vida de fluorescência do doador.

\section{TEORIA DE DEXTER}

O modelo de Dexter estende o modelo de Förster no sentido de incluir interações de troca e de multipolos, como dipolo-quadrupolo e quadrupolo-quadrupolo, cujas probabilidades de transferência de energia em função da distância são $R^{-8} \mathrm{e} R^{-10}$, respectivamente. Estas interações ocorrem se um ou ambos dipolos de transição são proibidos; por exemplo, a transferência de energia envolvendo estados tripletos de moléculas é frequentemente causada por interação de troca determinada pela sobreposição das funções de onda envolvidas. ${ }^{21}$ Diferentemente do mecanismo de Förster, o índice de refração do meio não exerce influência sobre os mecanismos de transferência de energia por troca ou por multipolos.

A teoria de transferência de energia de Dexter pode ser correlacionada com os processos de transferência de elétrons em reações de oxirredução de complexos de metais de transição, principalmente as que envolvem o mecanismo da esfera externa. A análise do mecanismo de esfera externa em reações de oxirredução de complexos depende basicamente de dois conceitos fundamentais: (i) aproximação de BornOppenheimer, a qual assume que o cálculo da distribuição eletrônica pode ser realizada assumindo-se a condição estacionária dos núcleos em questão e (ii) a transferência de elétrons é facilitada quando os núcleos dos complexos estiverem em uma determinada posição que torna iguais a energia dos elétrons dos sistemas. A partir destes conceitos pode-se dizer que a taxa de transferência de elétrons e a energia de ativação do processo dependem da habilidade dos sistemas, ou dos seus núcleos, de assumirem arranjos que levem à igualdade de energia de seus elétrons. Assumindo-se que os núcleos estão fixos no estado de transição (complexo ativado), é mais viável energeticamente que os sistemas alterem as distâncias de ligações metal-ligante, levando a estados intermediários de energia, facilitando a transferência de elétrons. Um dos exemplos didáticos da transferência de elétrons em reações de oxirredução envolvendo o mecanismo de esfera externa é a reação entre hexa-aquo complexos de ferro(II) e de ferro(III) e os fatores que determinam a taxa de transferência de elétrons podem ser entendidos pela Teoria de Marcus. Neste ponto os autores sugerem a leitura do trabalhado publicado por Marcus, em 1964. ${ }^{22}$

Yersin e coautore ${ }^{14}$ constataram que um complexo bidimensional de cianoaurato(I), quando intercalado por íons Eu(III), tem sua emissão totalmente suprimida por um eficiente processo não radiativo de transferência de energia, fazendo com que seja observada a emissão do íon Eu(III). Além disso, observaram que o aumento de pressão faz com que a sobreposição entre os espectros de emissão do doador e de absorção do receptor seja alterada; em outras palavras, o nível receptor do íon $\mathrm{Eu}(\mathrm{III})$ muda em função da pressão aplicada. Através da modelagem dos orbitais de fronteira envolvidos, foi sugerido que o provável mecanismo de transferência para este sistema seria o de Dexter, com taxas de transferência da ordem de até $10^{9} \mathrm{~s}^{-1}$, visto que a energia transferida é função da pressão. Por isso, este sistema foi chamado pelos autores de "sintonizável" por altas pressões.

Em seu trabalho Dexter ${ }^{12}$ mostrou que a taxa para a transferência de energia por mecanismo de troca é inversamente proporcional à exponencial dos raios médios dos orbitais envolvidos nos estados inicial ( $\left.D^{*} \mathrm{R}\right)$ e final ( $\left.\mathrm{DR} *\right)$. Sua teoria ainda foi desenvolvida levando em conta outros fatores, como a difusão de moléculas durante o tempo de vida do estado excitado. Confirmou sua teoria com experimentos envolvendo fósforos inorgânicos e propôs outros experimentos nesse sentido. A formulação de Dexter também foi estendida para calcular o rendimento do doador e o tempo de decaimento em função da concentração do receptor para transferência por mecanismo de troca. Ainda foi possível calcular a probabilidade do mecanismo de troca e expressá-la em termos de uma integral de sobreposição espectral.

A maior dificuldade prática no estudo do mecanismo de interação por multipolos é que não é possível obter a probabilidade de transferência através de propriedades ópticas das moléculas envolvidas. ${ }^{23}$ De acordo com o aspecto prático, a teoria de Förster e seu aprofundamento matemático são mais avançados que os da teoria de Dexter, visto que aquela equaciona variáveis cuja observação empírica é factível. Ou seja, enquanto a teoria de Förster correlaciona variáveis mensuráveis como o tempo de decaimento do doador e a integral de sobreposição espectral, as equações que descrevem a teoria de Dexter envolvem variáveis de difícil medição experimental, tais como a constante de interação orbital e os raios médios nos estados inicial e final dos orbitais envolvidos. Mesmo assim, Camargo e Nunes ${ }^{24}$ calcularam com propriedade os parâmetros de transferência de energia pelos mecanismos de dipolo-dipolo, dipolo-quadrupolo e quadrupolo-quadrupolo em vidros dopados com terras raras.

\section{MECANISMOS DE TRANSFERENCIA DE ENERGIA EM COMPLEXOS DE ÍONS TERRAS RARAS}

Muitos complexos contendo ligantes orgânicos ligados a íons metálicos apresentam interessantes processos de transferência de energia, como no caso do cristal de complexos de bipiridina de Os(II) e Ru(II) reportado por Yersin e Kratzer. ${ }^{25}$ Os autores elucidaram os mecanismos de troca de energia entre os complexos e atribuíram algumas propriedades a transferências de energia por troca (mecanismo de Dexter) de alta eficiência, graças à orientação dos orbitais de fronteira dos complexos no cristal, que diminui sua sobreposição e proíbe o mecanismo de transferência por ressonância de dipolos, desfavorecendo o mecanismo de Förster. Mesmo assim, o fato do doador e do receptor estarem tão próximos faz com que a transferência de energia por mecanismo de troca seja eficiente. Em outros sistemas, o doador e o receptor podem ser dois íons metálicos, como no caso

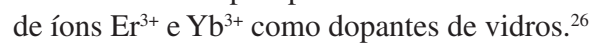

Entre os processos de transferência de energia envolvendo complexos de íons metálicos, aqueles que ocorrem dentro do complexo (intramoleculares) são especialmente importantes, ${ }^{27}$ tanto os processos de transferência ligante-metal como metal-ligante..$^{28}$

Complexos à base de íons terras raras (TR) apresentam aplicações variadas, devido as suas propriedades luminescentes. Em 1942, 
Weissman ${ }^{29}$ observou que o íon Eu(III), em complexos com certos ligantes orgânicos, apresenta uma emissão bem mais intensa quando o sistema é excitado na transição do ligante. Nestes sistemas, a energia absorvida pelo ligante é transferida ao íon Eu(III) e a emissão apresentada é característica das transições $4 \mathrm{f}^{\mathrm{n}}-4 \mathrm{f}^{\mathrm{n}}$ do íon terra rara. A intensificação da emissão do íon Eu(III) se deve principalmente a dois fatores: i) as regras de transição são mais relaxadas em sistemas deste tipo, graças ao aumento das contribuições, por exemplo, de tipo acoplamento dinâmico; ii) os níveis emissores ${ }^{5} \mathrm{D}_{\mathrm{J}}$ do íon Eu(III) são melhores populados por transferência de energia do que por excitação direta, pois o ligante é mais eficientemente excitado que o íon TR(III). Este efeito da intensificação da emissão do íon terra rara através da transferência de energia oriunda do ligante é conhecido como efeito antena, no qual o ligante absorve a radiação incidente e a transfere para o íon TR(III) ao qual está coordenado. ${ }^{30}$

Os modelos propostos por Förster e Dexter foram adaptados e aplicados em sistemas contendo íons TR(III) em fase condensada, como os desenvolvidos por Malta, ${ }^{31}$ Smentek e Hess ${ }^{32-34}$ e Kushida. ${ }^{35}$ Foram propostos alguns modelos de transferência de energia intramolecular para complexos deste tipo. ${ }^{36-38}$ As verificações espectroscópicas experimentais de diferentes sistemas levam a concluir que diferentes sistemas apresentam predominância de um ou de outro mecanismo. O processo de transferência de energia nos complexos de terras raras ocorre de três maneiras (Figura 6): a) o estado excitado $\mathrm{S}_{1}$ do ligante transfere energia não radiativa para um estado excitado $|4\rangle$ de maior energia do íon TR(III), que decai não radiativamente populando o estado emissor de menor energia $|2\rangle$, que então decai radiativamente para o estado fundamental ${ }^{36} \mathrm{~b}$ ) o estado excitado $S_{1}$ do ligante transfere energia não radiativamente para um estado excitado $|\mathbf{4}\rangle$ de maior energia do íon TR(III), que retrotransfere energia (transferência de energia metal-ligante) para o estado tripleto de menor energia do ligante $T_{1}$, o qual transfere energia para os estados excitados $|\mathbf{3}\rangle$ ou $|\mathbf{2}\rangle$ de energias mais baixas do íon TR(III), que então decaem radiativamente para o estado fundamental $;{ }^{37} \mathrm{c}$ ) o estado excitado $S_{1}$ do ligante, por mecanismo de cruzamento intersistemas decai não radiativamente para o estado excitado de menor energia $T_{1}$, que por sua vez transfere energia para os estados $|\mathbf{3}\rangle$ ou $|\mathbf{2}\rangle$ de energias mais baixas do íon TR(III), que então decaem radiativamente para o estado fundamental. ${ }^{38}$

Constata-se experimentalmente que o mecanismo (c) é o mais comumente encontrado em compostos de coordenação com os íons $\mathrm{Eu}(\mathrm{III})$ e $\mathrm{Tb}(\mathrm{III}){ }^{39-41}$ Neste mecanismo, a eficiência da conversão interna $S_{1} \rightarrow T_{1}$ está diretamente relacionada com a sobreposição energética entre estes dois estados. ${ }^{2}$ No entanto, certas moléculas apresentam uma grande diferença de energia entre os estados

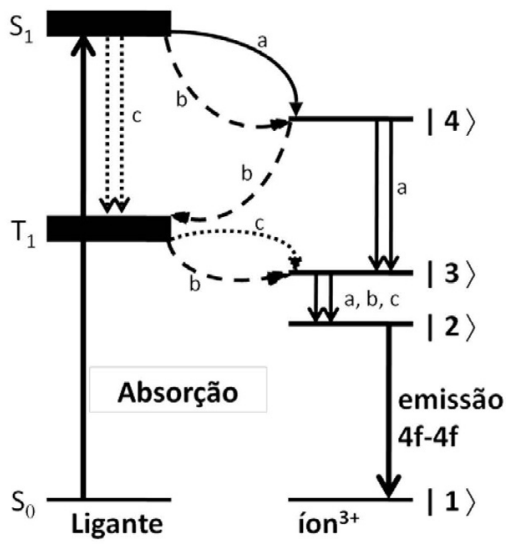

Figura 6. Mecanismos de transferência de energia em complexos com íons TR(III). Adaptada da ref. 38 excitados, fazendo com que sua luminescência seja oriunda de estados excitados singletos. ${ }^{42}$

Se a eficiência da conversão interna $S_{1} \rightarrow T_{1}$ de um dado sistema for muito baixa devido a uma grande diferença de energia entre estes dois estados, o estado $S_{1}$ do ligante pode popular um nível excitado de mais alta energia do íon TR(III), por exemplo, o nível ${ }^{5} \mathrm{D}_{4}$ do íon európio(III), de modo que os mecanismos (a) ou (b) possam ocorrer para alguns sistemas contendo íons TR(III) ${ }^{43}$ Se a diferença de energia entre o nível populado do íon TR(III) e o próximo nível abaixo deste for muito grande, o mecanismo (b) pode ser favorecido, se o estado $\mathrm{T}_{1}$ do ligante apresentar energia intermediária entre os dois níveis envolvidos.

Constatações experimentais ${ }^{44,45}$ obtidas através do estudo da luminescência de vários complexos mostram que, para uma elevada intensidade luminescente de complexos contendo o íon $\mathrm{Tb}$ (III), um fator determinante é que a energia do estado tripleto de mais baixa energia do ligante apresente energia maior do que $22500 \mathrm{~cm}^{-1}$; caso contrário, a retrotransferência de energia metal-ligante aumenta até valores significativos, o que diminui sensivelmente a intensidade da luminescência do íon $\mathrm{Tb}(\mathrm{III})$ e favorece a fosforescência do ligante. Já no caso de complexos contendo o íon Eu(III), é necessário que o nível de mais baixa energia do estado emissor do ligante apresente energia ligeiramente maior que o nível receptor do íon Eu(III). Neste caso, a taxa de retrotransferência é menor do que no caso dos complexos com o íon $\mathrm{Tb}(\mathrm{III})$, pois o tempo de vida do seu estado ${ }^{5} \mathrm{D}_{0}$ do íon $\mathrm{Eu}(\mathrm{III})$ é menor do que o tempo de vida do estado ${ }^{5} \mathrm{D}_{4}$ do íon $\mathrm{Tb}(\mathrm{III}),{ }^{46}$ pois a diferença energética entre os estados emissores e o estado fundamental é menor para o caso do íon európio(III).

Crosby e coautores ${ }^{36}$ observam que a transferência de energia por mecanismo de Förster nestes sistemas é pouco provável, devido à necessidade de sobreposição espectral entre a emissão do ligante e a absorção do íon TR(III) dos compostos. Sabe-se que normalmente a sobreposição no caso de complexos de íons terras raras está na ordem de 0,05 . Além disso, se o mecanismo envolvido fosse de transferência de carga seguida de mecanismo de Förster, dever-se-ia observar um deslocamento para menor energia do estado $T_{1}$ do ligante, especialmente no caso do complexo com Yb(III) (cujo nível emissor apresenta energia consideravelmente menor que $\mathrm{T}_{1}$ ), mas esse deslocamento não é observado. Por fim, observam que a natureza da ligação ligante-íon TR(III) tem grande importância na luminescência. Assim, concluem que o mecanismo de luminescência envolve a sobreposição orbital, mantendo-se a multiplicidade de spin total, ou seja, atribuem o fenômeno ao mecanismo de Dexter.

Lima e coautores ${ }^{47}$ estudaram quantitativamente a transferência de energia em híbridos orgânico-inorgânicos contendo íons Eu(III) e concluíram que a transferência de energia da matriz para o íon metálico se dá tanto partindo dos estados excitados como via mecanismos dipolo-dipolo, dipolo-multipolo e mecanismo de troca. Ainda puderam determinar o canal luminescente mais eficaz para o sistema e confrontaram a viabilidade dos mecanismos de Förster e de Dexter (Figura 7) para o sistema em questão, chegando à conclusão de que o mecanismo de troca (Dexter) é dominante.

Para distâncias de transferência de energia menores do que $4 \AA$, o mecanismo de Dexter (Figura 7a) deve ser considerado. No entanto, deve-se tomar precauções ao calcular as taxas de transferências, devido à existência das regras de seleção que regem as transições intraconfiguracionais 4f-4f, o que pode gerar grandes diferenças entre os valores previstos. ${ }^{48}$ As regras de seleção para os mecanismos de troca de energia envolvendo os números quânticos de momento angular total (J) dos íons lantanídeos são: (i) $|\Delta \mathrm{J}|=0$ ou 1 - mecanismo de troca, (Figura 7a) $|\Delta \mathrm{J}| \leq 6$ - dipolo-dipolo e dipolo-multipolo, ${ }^{45}$ (Figura $7 \mathrm{~b}$ ) excluindo-se $\mathrm{J}=\mathrm{J}$ ' $=0$ para ambos os casos. No caso do íon európio(III) os níveis excitados ${ }^{5} \mathrm{D}_{2},{ }^{5} \mathrm{~L}_{6},{ }^{5} \mathrm{G}_{6} \mathrm{e}{ }^{5} \mathrm{D}_{4}$ são populados 


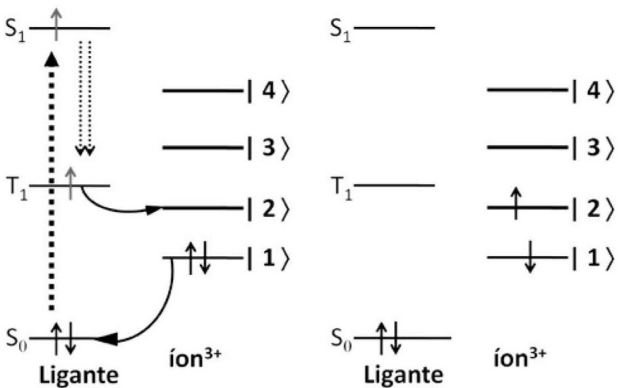

Dexter

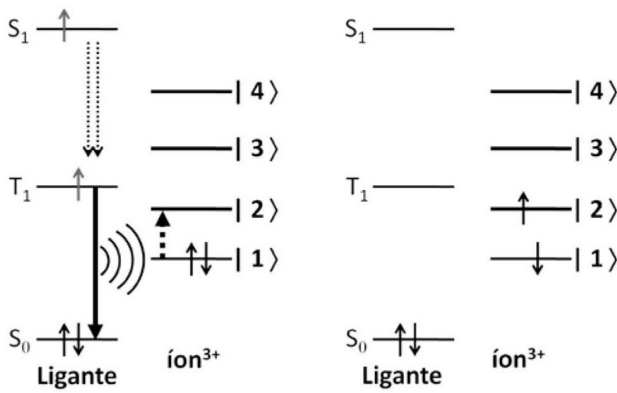

Förster

Figura 7. Mecanismos de transferência de energia de Dexter e Förster

via transferência ligante-íon principalmente pelo mecanismo de transferência multipolar e o nível ${ }^{5} \mathrm{D}_{1}$ deve ser populado principalmente pelo mecanismo de troca.

\section{CONCLUSÃO}

Os principais modelos de transferência não radiativa de energia inter e intramolecular foram explorados e exemplificados, com enfoque em fase condensada.

O modelo de Perrin, apesar de estar fundamentado no princípio real da transferência de energia por ele observada, falha ao utilizar a mecânica clássica como ferramenta matemática. Assim como Perrin, Förster descreveu a transferência de energia pela interação entre os dipolos elétricos do doador e do receptor, mas desenvolveu sua teoria utilizando ferramentas mecânico-quânticas, o que o permitiu prever valores muito próximos dos encontrados experimentalmente. Mas alguns fenômenos de transferência de energia fugiam á previsão de Förster e, então, Dexter expandiu o modelo de Förster para os fenômenos onde há troca de elétrons ou interação multipolar entre doador e receptor. Assim, a transferência de elétrons de Dexter é observada quase que exclusivamente em distâncias muito curtas ou quando o mecanismo de Förster é proibido. Vale ressaltar que a transferência de energia nestes sistemas via mecanismo de troca vai além do comportamento exponencial simples adotado por Dexter. ${ }^{48}$

Transferência de energia intramolecular é o princípio da fotoluminescência de complexos contendo íons terras raras. Vias de transferência e retrotransferência foram discutidas e três mecanismos principais foram propostos na literatura, cada um deles fundamentado experimentalmente. A partir de tais observações, conclui-se que os mecanismos de fato ocorrem, mas que normalmente um é privilegiado por diferenças de energia ou por taxas de transferência que são regidas, também, pelas regras de seleção envolvendo a variação do número quântico de momento angular total.

O mecanismo de Förster tem menor importância, visto que as transições intraconfiguracionais $4 \mathrm{f}^{\mathrm{n}}-4 \mathrm{f}^{\mathrm{n}}$ não apresentam um perfil espectral que permita uma boa sobreposição com a banda de emissão do ligante envolvido. De qualquer modo, todos os modelos propostos concordam com a importância para a luminescência do estado $\mathrm{T}_{1}$ do ligante e dos estados excitados de maior energia do íon TR(III).

\section{REFERÊNCIAS}

1. Berlman, I. B.; Energy transfer parameters of Aromatic compounds, Academic Press: New York and London, 1973.

2. Souza, E. R.; Silva, I. G. N.; Teotonio, E. E. S.; Felinto, M. C. F. C.; Brito, H. F.; J. Lumin. 2010, 130, 283.

3. Kallmann, H.; Furst, M.; Phys. Rev. 1950, 79, 857.

4. Matsushita, S.; Nakata, H.; Kuboi, Y.; Tateyama, M.; J. Biol. Chem. 2010, 285, 10291.

5. Loura, L. M. S.; Almeida, R. F. M.; Silva, L. C.; Prieto, M.; Biochim. Biophys. Acta 2009, 1788, 209.

6. Medintz, I. L.; Mattoussi, H.; Phys. Chem. Chem. Phys. 2009, 11, 17.

7. Fan, L. J.; Zhang, Y.; Murphy, C. B.; Angell, S. E.; Parker, M. F. L.; Flynn, B. R.; Jones Jr, W. E.; Coord. Chem. Rev. 2009, 253, 410.

8. Mao, Z.; Wang, D.; Inorg. Chem. 2010, 49, 4922.

9. Perrin, J.; Comptes Rendus Hebdomadaires des Seances de l'Academie des Sciences 1927, 184, 1097.

10. Förster, T.; Annalen der physik 1948, 2, 55.

11. Stryer, L.; Haugland, R. P.; Proceedings of the National Academy of Sciences of the United States of America 1967, 58, 719.

12. Dexter, D. L.; J. Chem. Phys. 1953, 21, 836.

13. Novo, J. B. M.; Dias Jr., L. C.; Quim. Nova 2011, 34, 707

14. Yersin, H.; Trümbach, D.; Strasser, J.; Inorg. Chem. 1998, 37, 3209.

15. Noomnarm, U.; Clegg, R. M.; Photosynth. Res. 2009, 101, 181.

16. McGlynn, S. P.; Azumi, T.; Kinoshita, M.; Molecular spectroscopy of the triplet state, Prentice-Hall: New Jersey, 1969.

17. Lakowicz, J. R.; Principles of Fluorescence Spectroscopy, Kluwer Academic/ Plenum Publishers: New York, 1999.

18. Mullert, D. F.; Houston, P. L.; J. Phys. Chem. 1981, 85, 3563.

19. Oliveira, H. P. M.; Machulek Jr., A.; Legendre, A. O.; Gehlen, M. H.; Quim. Nova 2003, 26, 564.

20. Johnson, P. C.; Offen, H. W.; J. Chem. Phys. 1972, 57, 1473.

21. Agranovich, V. M.; Galanin, M. D.; Electronic excitation energy transfer in condensed matter, North-Holland Publishing Company: Amsterdam, New York, Oxford, 1982.

22. Marcus, R. A.; Annu. Rev. Phys. Chem. 1964, 15, 155.

23. Andrews, D. L.; Demidov, A. A., eds.; Resonance Energy transfer, John Wiley \& Sons: West Sussex, 1999.

24. Camargo, A. S. S.; Nunes, L. A. O.; Quim. Nova 2008, 31, 2083.

25. Yersin, H.; Kratzer, C.; Coord. Chem. Rev. 2002, 229, 75.

26. Ribeiro, C. T. M.; Zanatta, A. R.; Sartori, J.; Nunes, L. A. O.; Messaddeq, Y.; Quim. Nova 1998, 21, 521.

27. Martins, R. F.; Neri, C. R.; de Sousa Fo , P. C.; Serra, O. A.; de Oliveira, K. T.; Quim. Nova 2010, 33, 2118.

28. Sá, G. F.; Malta, O. L.; Donegá, C. M.; Simas, A. M.; Longo, R. L.; Santa-Cruz, P. A.; Silva Jr., E. F.; Coord. Chem. Rev. 2000, 196, 165.

29. Weissman, S. I.; J. Chem. Phys. 1942, 10, 214.

30. Silva, F. R. G.; Malta, O. L.; Reinhard, C.; Güdel, H.-U.; Piguet, C.; Moser, J. E.; Bünzli, J.-C. G.; J. Phys. Chem. A 2002, 106, 1670.

31. Malta, O. L.; Chem. Phys. Lett. 1982, 87, 27.

32. Smentek, L.; Hess Jr, B. A.; J. Alloys Compd. 2000, 300-301, 165.

33. Smentek, L.; Hess Jr, B. A.; J. Alloys Compd. 2001, 315, 1.

34. Smentek, L.; Hess Jr, B. A.; J. Alloys Compd. 2002, 336, 56

35. Kushida, T.; J. Phys. Soc. Jpn. 1973, 34, 1318.

36. Crosby, G. A.; Whan, R. E.; Alire, R. M.; J. Chem. Phys. 1961, 34, 743.

37. Bhaumik, M. L.; El-Sayed, M. A.; J. Chem. Phys. 1965, 42, 787.

38. Kleinerman, M.; J. Chem. Phys. 1969, 51, 2370. 
39. Souza, E. R.; Dissertação de Mestrado, Universidade de São Paulo, Brasil, 2008

40. Crosby, G. A.; Mol. Cryst. 1966, 1, 37.

41. Buono-Core, G. E.; Li, H.; Marciniak, B.; Coord. Chem. Rev. 1990, 99 , 55

42. Zhang, Y.; Aslan, K.; Previte, M. J. R.; Geddes, C. D.; Chem. Phys. Lett. 2006, $432,528$.

43. Alaoui, I. M.; J. Phys. Chem. 1995, 99, 13280.

44. Latva, M.; Takalo, H.; Mukkala, V.-M.; Matachescuc, C.; RodriguezUbisd, J. C.; Kankare, J.; J. Lumin. 1997, 75, 149.
45. Lima, P. P.; Malta, O. L.; Alves Jr., S.; Quim. Nova. 2005, 28, 805.

46. Bünzli, J.-C. G.; Choppin, G. R.; Lanthanide probes in life, chemical and earth sciences, Elsevier Science Publishers: New York, 1989.

47. Lima, P. P.; Nobre, S. S.; Freire, R. O.; Alves Jr., S.; Ferreira, R. A. S.; Pischel, U.; Malta, O. L.; Carlos, L. D.; J Phys. Chem. C 2007, 111, 17627.

48. Malta, O. L.; J. Non-Cryst. Solids 2008, 354, 4770. 